\section{As diferenças e as semelhanças entre o Fundo Soberano do Brasil e os fundos soberanos internacionalmente consagrados.}

\author{
Jayme Luiz Gomes Fialho \\ Faculdade Novos Horizontes \\ jfialho@anp.gov.br \\ Alfredo Alves de Oliveira Melo \\ Faculdade Novos Horizontes \\ diretoria@unihorizontes.br
}

ISSN: 1984-6266

Recebimento:

28/12/2015

Aprovação:

01/08/2016

Editor responsável pela aprovação do artigo:

Dr. Jorge Eduardo Scarpin

Editor responsável pela edição do artigo:

Dr. Flaviano Costa

Avaliado pelo sistema:

Double Blind Review

A reprodução dos artigos, total ou parcial, pode ser feita desde que citada a fonte.

\title{
Resumo
}

Em dezembro de 2008, foi criado o Fundo Soberano do Brasil (FSB) com aporte inicial de $\mathrm{R} \$ 14,2$ bilhões. Este artigo analisa as diferenças e as semelhanças entre o FSB e os conceitos internacionalmente consagrados para os Fundos Soberanos. Para tal, são identificadas as principais características dos Fundos Soberanos e, em seguida, do FSB. Num momento posterior, as características identificadas são confrontadas a fim de verificar se o FSB é aderente às boas práticas internacionais.

Palavras-chave: Fundos Soberanos. Fundo Soberano do Brasil. Ativos financeiros. 


\title{
DIFFERENCES AND SIMILARITIES BETWEEN THE SOVEREIGN FUND OF BRAZIL AND THE SOVEREIGN WEALTH FUNDS INTERNATIONALLY RECOGNIZED
}

\begin{abstract}
In December 2008, the Sovereign Fund of Brazil (FSB) was created with an initial contribution of $\mathrm{R} \$ 14.2$ billion. This article examines the differences and similarities between the FSB and internationally recognized concepts for Sovereign Wealth Funds (SWFs). To this end, it identifies the main characteristics of SWFs and FSB. At a later point, the identified features are confronted in order to verify if the FSB is adhering to international best practices.
\end{abstract}

Keywords: Sovereign Wealth Funds. Sovereign Fund of Brazil. Financial assets.

\section{Introdução}

Fundo Soberano é uma definição do acúmulo de reservas internacionais pelos países, mantidas para estabilização econômica e maximização dos rendimentos. Estima-se que atualmente os recursos dos Fundos Soberanos sejam de aproximadamente US $\$ 6,4$ trilhões, dos quais $60 \%$ têm origem na exploração do petróleo, conforme informações obtidas junto ao Sovereign Wealth Fund Institute (SWF Institute).

Com a publicação da Lei n 11.887/2008, o Fundo Soberano do Brasil (FSB) foi criado com o objetivo de fomentar projetos estratégicos, mitigar efeitos de ciclos econômicos, formar poupança pública e promover investimentos em ativos no Brasil e no exterior.

Este artigo pretende apresentar as diferenças e as semelhanças entre as características internacionalmente consagradas para os Fundos Soberanos e o FSB, com o objetivo de verificar se o FSB é aderente aos padrões internacionais.

Os aportes iniciais no FSB somaram $\mathrm{R} \$ 14,2$ bilhões, em 2008. Tal volume financeiro é, per se, justificativa suficiente para o estudo do tema. Em adição, analistas da PricewaterhouseCoopers estimam que os ativos totais mundiais sejam da ordem de US $\$ 64$ trilhões, dos quais 10\% estariam sob a gestão dos Fundos Soberanos. Na esfera acadêmica, pretende-se atualizar os estudos que eclodiram entre 2008 e 2010 sobre 0 FSB. Complementarmente, os Fundos Soberanos estão financiando projetos sociais, ambientais e de produção de alimentos, sobretudo na África subsaariana.

A questão que se pretende elucidar está relacionada à aproximação entre o FSB e os conceitos internacionalmente consagrados de Fundos Soberanos. Quais são as características do FSB que o aproximam dos Fundos Soberanos? E quais são os mecanismos operacionais que possam, eventualmente, distanciar 0 FSB e os Fundos Soberanos?

Num primeiro momento, são apresentadas as características gerais dos Fundos Soberanos e, em particular, as características do FSB. No momento seguinte, o FSB é confrontado com os padrões internacionalmente consagrados, para, enfim, permitir concluir se o FSB está adequadamente concebido.

\section{Referencial Teórico}

A seguir, apresentam-se os principais conceitos e fundamentos que possam permitir uma boa aproximação entre os Fundos Soberanos e o FSB. 


\section{As diferenças e as semelhanças entre o Fundo Soberano do Brasil e os fundos soberanos internacionalmente consagrados}

\subsection{Definição de Fundos Soberanos}

Fundo Soberano é um grande volume de ativos financeiros de propriedade do governo. 0 termo surgiu em 2005 para caracterizar reservas internacionais mantidas pelos países para diversificar suas aplicações e garantir maior retorno sobre o capital investido.

O SWF Institute é uma organização que estuda os Fundos Soberanos e o impacto que causam na economia global. No site mantido pela organização, definem-se Fundos Soberanos como fundos especiais instituídos para canalizar investimentos estatais, compostos de ativos tais como ações, títulos, imóveis ou outros.

Cada Fundo Soberano possui motivadores próprios para sua criação, mas pode atender múltiplos propósitos: [1] proteger e estabilizar o orçamento e a economia da volatilidade das receitas das exportações, auxiliando o Banco Central a dissipar o excesso de liquidez e fornecendo sustentação para o crescimento econômico de longo prazo; [2] diversificar os investimentos com origem em receitas de exportação de recursos naturais não renováveis, obtendo maiores resultados do que os alcançados com os investimentos tradicionais; [3] aumentar a poupança para as gerações futuras e financiar o desenvolvimento social e econômico; e [4] estratégia política.

De acordo com analistas do Fundo Monetário Internacional (FMI) e Das, Mulder, Sy e Lu (2009, p. 5), os Fundos Soberanos são fundos de investimento com um propósito especial, de propriedade do Governo Central. Segundo os autores, "os Fundos Soberanos operam investimentos de longo prazo e possuem menor aversão aos riscos, se comparados aos investimentos efetuados com as reservas internacionais".

Os Fundos Soberanos são fundos de investimentos como quaisquer outros que existem há vários anos, diferenciando-se apenas pela propriedade do fundo que, nestes casos, pertence ao Governo. No senso comum, existem dois propósitos fundamentais, quais sejam: [1] estabilização: fundos anticíclicos que tentam blindar a economia local contra crises nacionais e/ou internacionais, bem como minimizar os efeitos da volatilidade dos preços das commodities e; [2] poupança: quando os fundos são formados com a exportação de recursos naturais não renováveis, são constituídas reservas para as gerações futuras, que podem ser investimentos em educação, investimentos em infraestrutura ou reserva de capitais.

Vale observar que as reservas de capitais são, preferencialmente, mantidas no mercado externo. Não existem regras rígidas pré-estabelecidas para definir o momento certo para a criação do Fundo Soberano. A análise do balanço público utilizando ferramentas tais como o gerenciamento de ativos e passivos e a gestão do déficit público podem auxiliar a otimização da alocação dos ativos. Mas, na prática, o estabelecimento de um Fundo Soberano é uma decisão ad hoc, quando uma massa crítica de superávit fiscal ou no balanço de pagamentos é alcançada. Isso explica porque os Fundos Soberanos são, geralmente, criados após o aumento dos preços das commodities, como aconteceu na década de 1970, e novamente na segunda metade da década anterior.

Segundo Das et al. (2009, p.6), "quando um país descobre uma reserva de petróleo, é disparado um processo que considera as implicações da nova riqueza". É considerado qual o nível adequado de receitas de modo que a receita excedente possa ser aplicada. Os tomadores de decisões irão alocar o excesso de reservas em aplicações distintas, com maior tolerância ao risco. A questão é quando (em qual nível) as reservas estão adequadas?

Tipicamente, grandes reservas financeiras propiciam aos governos a oportunidade de diversificar os investimentos. Não existe, entretanto, um padrão para se determinar o volume de reservas a partir do qual os investimentos podem ser diversificados. Assim, o volume ótimo de reservas destinado à diversificação de investimentos deve ser acertado entre o Banco Central e o Governo Central, de modo que o nível de reservas internacionais que servem de seguro para a economia não seja sacrificado.

A seguir será analisado o cenário macroeconômico no qual se assentam os Fundos Soberanos.

RC\& C - Revista Contabilidade e Controladoria, Curitiba, v. 9, n. 1, p. 112-123, jan./abr. 2017. 


\subsection{Condições macroeconômicas que justificam a criação de Fundos Soberanos}

Após deflagradas as crises econômicas da década de 1990 (México em 1994, "Tigres Asiáticos" em 1997, Rússia em 1998 e Brasil em 1999), os países buscaram blindagens para suas economias contra crises internacionais, acumulando reservas cambiais que, ao longo da década de 2000 , atingiram níveis superiores aos necessários (Caparica, 2010).

Os excessos de recursos internacionais provocam estragos na economia de um país, tais como pressão inflacionária e apreciação cambial, tornando o produto nacional pouco competitivo no mercado internacional e provocando a necessidade de adoção de medidas estabilizadoras.

A primeira opção para utilização dos recursos acumulados é o pagamento da dívida externa. A segunda opção é o gerenciamento das reservas numa perspectiva de longo prazo, com portfólio diversificado, onde 0 trade off entre ganhos e risco é criteriosamente analisado. A terceira opção é estabelecer o Fundo Soberano.

Diante deste cenário, os países que acumularam as condições adequadas optaram pela criação de Fundos Soberanos. E o desequilíbrio prolongado no sistema financeiro global tem contribuído para a expansão dos Fundos Soberanos criados e para a proliferação de novos Fundos Soberanos.

Países emergentes são grandes produtores de commodities e sofreram forte demanda na primeira metade da década de 2000 para sustentar o crescimento econômico, notadamente na China. Investimentos estrangeiros têm sido realizados nos países emergentes em busca de melhor remuneração do capital. 0 influxo e 0 acúmulo de reservas internacionais nestes países provocam excesso de liquidez. Alguns desses países optaram pela criação de Fundos Soberanos, emprestadores de última instância com baixa aversão ao risco.

Além dos pontos abordados, acrescenta-se que os países que exploram recursos naturais não renováveis (notadamente o petróleo) se preocupam com a manutenção de reservas de ativos para as gerações futuras. Assim, mesmo que não atendidos os demais requisitos macroeconômicos para a criação do Fundo Soberano, algumas economias maduras e emergentes que exploram recursos naturais não renováveis optaram pela criação de Fundos Soberanos. Sob esse aspecto repousam várias críticas. Por que manter reservas internacionais se o país precisa de investimentos em infraestrutura, saúde, educação, segurança etc.? Por que aplicar em títulos da dívida pública de governos transnacionais se o endividamento interno está elevado? Assim, percebe-se que a decisão de criar o Fundo Soberano é tanto política quanto técnica.

\subsection{Características dos Fundos Soberanos}

Apesar de não haver uma regra única internacional para a concepção dos Fundos Soberanos, as boas práticas internacionais permitem sugerir uma tipologia para os Fundos Soberanos (Magalhães, 2010).

Fonte de financiamento: superávit fiscal, concessões e privatizações; saldo positivo no Balanço de Pagamentos, acúmulo de reservas externas; recursos oriundos da exploração de recursos naturais não renováveis.

Disciplina fiscal: Freitas $(2009$, p. 3) afirma que o Fundo Soberano "não pode ser visto como uma solução para o desequilíbrio fiscal existente no País. Como mostra a experiência internacional, é a disciplina fiscal que leva ao sucesso de um fundo, e não o contrário". A instituição do Fundo Soberano não conduz à maior disciplina fiscal.

Reservas internacionais: não se confundem com as reservas que o Banco Central mantém para executar política cambial e operacionalizar transações comerciais internacionais.

Elevado retorno do capital investido: Das et al. (2009, p. 11) afirmam que alguns fundos são criados com o propósito de maximizar o retorno sobre o capital investido. A maximização do retorno considera o risco 


\section{As diferenças e as semelhanças entre o Fundo Soberano do Brasil e os fundos soberanos internacionalmente consagrados}

envolvido nas operações. A longevidade desses fundos não é clara e "a tolerância ao risco e horizonte de investimento muitas vezes permanecem implícitos".

Transparência: os pesquisadores Carl Linaburg e Michael Maduell do SWF Institute desenvolveram um critério para analisar a transparência dos Fundos Soberanos, que recebem notas de 0 a 10, conhecido como Índice de Transparência Linaburg-Maduell. 0 método para avaliar o comportamento ético dos Fundos Soberanos consiste em atribuir um ponto a cada um dos dez atributos considerados relevantes para a transparência dos Fundos Soberanos. Os princípios analisados são o histórico do fundo, o relatório de auditoria independente anual, a participação societária em holdings, o valor de mercado e retorno sobre valor aplicado, os padrões éticos, as estratégias claras, a divulgação do contato para informações, os gerentes externos, site na internet e localização física do escritório.

Saques: deverá haver expressa previsão legal que permita saques no Fundo Soberano para cobrir eventuais déficits no Balanço de Pagamentos ou outros objetivos legítimos.

Oportunidade política: os mercados emergentes, notadamente os países dos BRICS (conceito formulado pelo economista-chefe da Goldman Sachs, Jim O'Neil, em 2001, do agrupamento entre Brasil, Rússia, Índia, China e África do Sul), acumularam reservas bilionárias na década de 2000, destacadamente até 0 ano de 2007 (Magalhães, 2010). O Brasil passou a ser credor externo líquido e o Ministério da Fazenda manifestou sua intenção em criar um Fundo Soberano, seguindo os exemplos recentes de Rússia e China. Murphy (2012) considera que fins políticos são um importante fator na decisão de investimentos dos Fundos Soberanos. Al-Hassan, Papaioannou, Skancke e Sung (2013, p.10) nos ensinam que o modelo fundamentado na oportunidade política não é recomendado, pois os Fundos Soberanos são um processo técnico, e não político. Entretanto, os autores concluem que "para países com graves restrições de capital humano, esta pode ser a única solução viável". Entenda-se dessa afirmação que a não criação do Fundo Soberano pode levar ao consumo do capital acumulado, pela corrupção e ganância política desenfreada.

Vale destacar que o SWF Institute classifica o FSB como um fundo não commodity, estabelecido em 2008, com aporte de US\$5,3 bilhões e nota 9 no Índice de Transparência Linaburg-Maduell.

\subsection{Fundo Soberano do Brasil - FSB}

A proposta do Governo Federal de criar o Fundo Soberano do Brasil - FSB foi recebida com ressalvas, pois, segundo os analistas, o Brasil não apresentaria as condições necessárias para tal iniciativa: superávit nominal e saldo positivo na Conta Corrente (Lopes, 2009). Outrossim, tanto as fontes de recursos como as destinações das aplicações também estariam incompatíveis com as boas práticas internacionais.

Caparica (2010, p. 45) colabora com a análise sobre o resultado em Conta Corrente argumentando que "as taxas de poupança doméstica são insuficientes para financiar os investimentos, tornando necessário absorver poupança estrangeira".

A despeito de qualquer outro argumento, o Fundo Soberano do Brasil foi criado pela Lei 11.887/2008 e, com a edição simultânea da Medida Provisória $n^{\circ} 452 / 2008$, foram emitidos $R \$ 14,2$ bilhões em títulos da dívida pública como dotação inicial. A Secretaria do Tesouro Nacional (STN), responsável pela gestão do FSB, define que

\footnotetext{
A participação da economia brasileira tem sido cada vez mais ativa no cenário mundial. Neste contexto, dada a crescente necessidade de fomentar projetos estratégicos, mitigar efeitos de ciclos econômicos, formar poupança pública e promover investimentos em ativos no Brasil e no exterior, foi criado, pela Lei $n^{0} 11.887$, de 24 de dezembro de 2008, o Fundo Soberano do Brasil - FSB. O FSB é um fundo especial de natureza contábil e financeira, vinculado ao Ministério da Fazenda.
} 
A Lei $11.887 / 2008$ prevê em seu Art. $2^{\circ}$ que os recursos do FSB serão utilizados em investimentos e inversões financeiras, através da aquisição de ativos financeiros externos e integralização das cotas do Fundo Fiscal de Investimentos e Estabilização (FFIE), responsável pela operacionalização do FSB.

As inversões financeiras são um grupo de natureza da despesa que abrange os gastos com aquisição de imóveis em utilização, aquisição de bens para revenda, aquisição de títulos de crédito de títulos representativos de capital já integralizado, constituição ou aumento de capital de empresas concessão de empréstimos, entre outros.

O mesmo dispositivo legal determina em seu Art. $4^{\circ}$ que as fontes de recursos do FSB podem ser recursos orçamentários da União, ações das sociedades de economia mista federal, os resultados de suas aplicações financeiras e títulos da dívida pública. Os resgates deveriam atender "exclusivamente o objetivo de mitigar os efeitos dos ciclos econômicos".

Conforme demonstrado pelo Relatório de Desempenho do Fundo Soberano do Brasil, o Governo emitiu aproximadamente $\mathrm{R} \$ 14$ bilhões em títulos da dívida pública para capitalizar o FSB. Os recursos ficaram investidos em títulos da dívida pública até o $3^{\circ}$ trimestre de 2010, quando foram utilizados para aquisição de ações da Petrobras e do Banco do Brasil.

Durante o período de 2002 a 2010, a taxa de câmbio do Real frente ao Dólar sofreu forte apreciação (Figura 1) provocada pela entrada de recursos externos atraídos tanto pelos investimentos diretos quanto pela atrativa taxa de juros praticada pelo Governo brasileiro). Com o fluxo de capital estrangeiro, o Brasil passou a ser credor externo líquido, mas a relação reservas/dívida ficou muito próxima à unidade (segundo o $\mathrm{BCB}$, em maio de 2014, a relação reservas/dívida estava menor que a unidade). A Doença Holandesa (caracterizada pela crônica sobreapreciação da taxa de câmbio de um país causada pela exploração de recursos abundantes e baratos, cuja produção e exportação é compatível com uma taxa de câmbio claramente mais apreciada que a taxa de câmbio que torna competitivas internacionalmente as demais empresas de bens comercializáveis que usam a tecnologia mais moderna existente no mundo) não apresentou nenhum sintoma no Brasil. A crise dos mercados deflagrada a partir de 2008 foi gradualmente invertendo esse cenário, notadamente após 2011. Assim, a blindagem que poderia supostamente ser oferecida pelo FSB contra a invasão de recursos externos tornou-se absolutamente inócua.

Figura 1

Variação cambial do Real frente ao Dólar

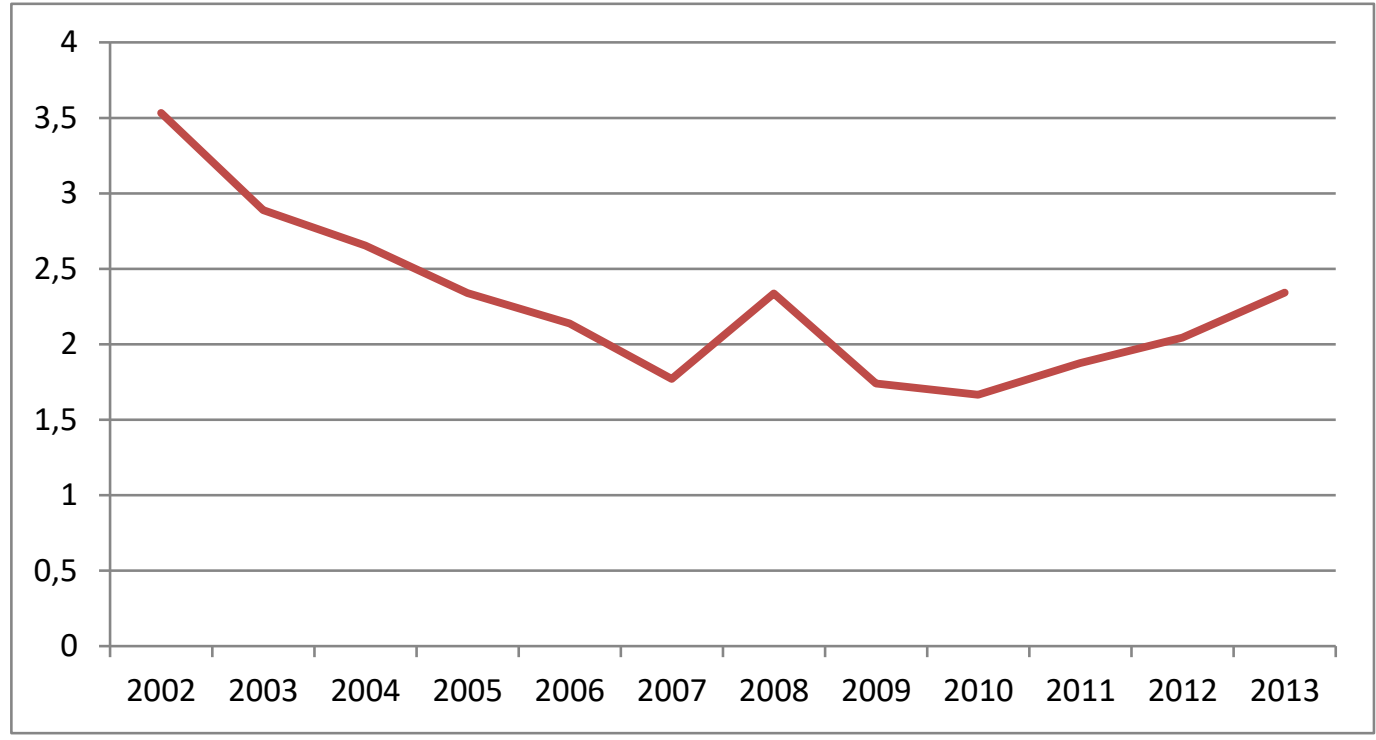

Fonte: Dos autores, a partir de dados encontrados em www.bcb.gov.br. 


\section{As diferenças e as semelhanças entre o Fundo Soberano do Brasil e os fundos soberanos}

internacionalmente consagrados

As taxas de juros praticadas no mercado de títulos da dívida pública brasileira eram, na ocasião, as maiores do mundo (Vieira, 2008). Logo, não havia no mercado internacional nenhum investimento que pudesse ser mais atrativo do que o resgate de títulos da dívida pública, a despeito da eventual pressão inflacionária.

O déficit nominal brasileiro é uma das características da indisciplina fiscal (Figura 2). Freitas (2009) destaca que "fundos de estabilização ou de poupança não criam um mecanismo capaz de estabilizar os gastos ou de preservar riqueza. Para um fundo cumprir adequadamente seus objetivos, é necessário que haja um compromisso do governo com disciplina fiscal".

Figura 2

Resultado fiscal nominal e primário

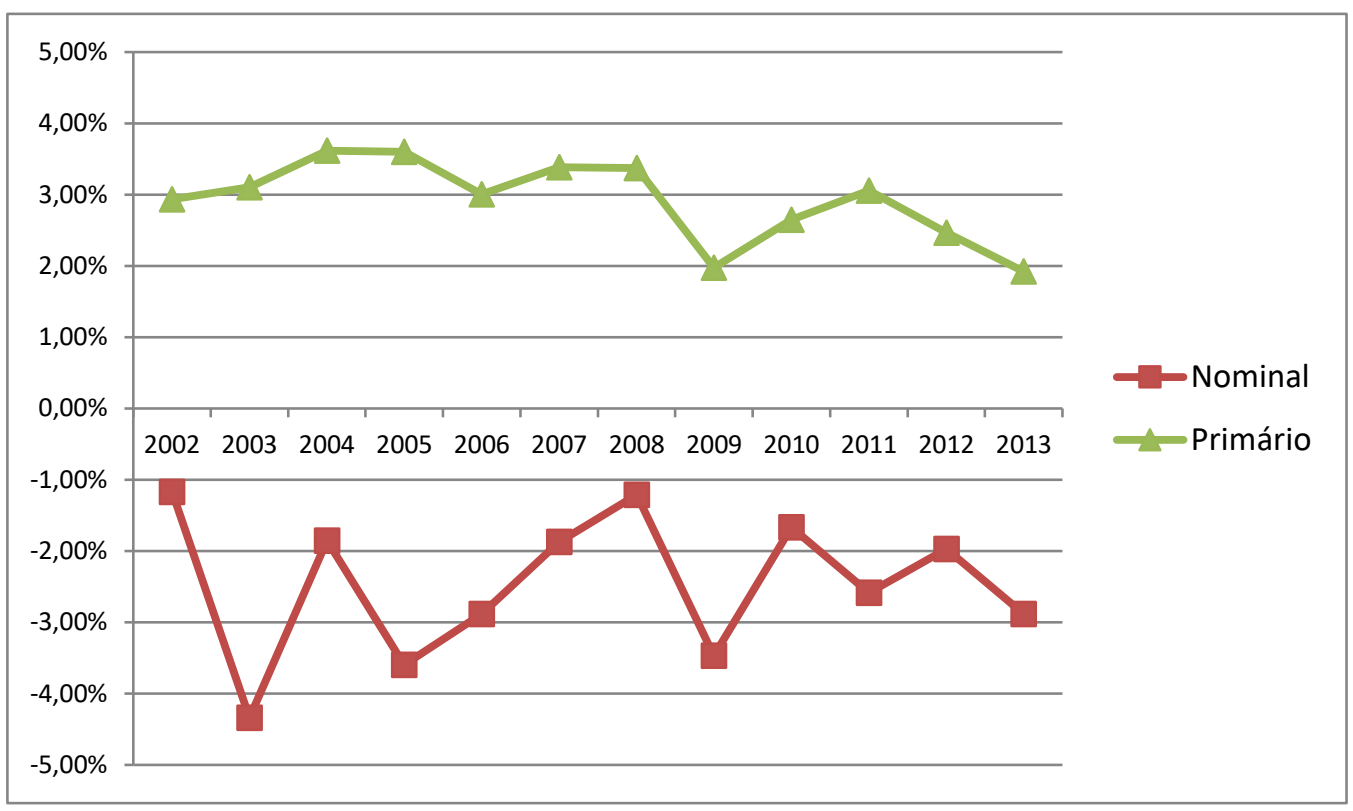

Fonte: Dos autores, a partir de dados encontrados em www.bcb.gov.br.

Os objetivos a que o FSB se propunha (fomentar projetos estratégicos, mitigar efeitos de ciclos econômicos, formar poupança pública e promover investimentos em ativos no Brasil e no exterior) não foram alcançados. E em dezembro de 2012, o FSB sofreu seu maior revés, com o resgate de cotas do FFIE no montante de $\mathrm{R} \$ 12,4$ bilhões. Os recursos resgatados foram aplicados temporariamente em subconta remunerada do FSB na Conta Única do Tesouro Nacional (CTU). Na prática, isso significa sacar do FSB para mascarar 0 atendimento das metas fiscais, contrariando a Regra de Ouro (Art. 44 da Lei Complementar 101/200 - Lei de Responsabilidade Fiscal) da contabilidade pública.

\section{Metodologia}

A pesquisa é essencialmente qualitativa de natureza exploratória e se insere no paradigma interpretativista (Morgan, 2005). Para atender as necessidades da pesquisa, utilizam-se a revisão bibliográfica e a coleta de dados secundários. A compreensão que se procura obter qualitativamente é a aproximação (ou distanciamento) entre o FSB e os Fundos Soberanos internacionalmente consagrados. Para tal, o estudo investiga o conhecimento sedimentado sobre os Fundos Soberanos e procura construir uma relação com 0 arcabouço legal brasileiro que criou o FSB.

Os Fundos Soberanos passaram a ser assim conhecidos a partir de 2005. O arcabouço legal e regulatório que cria e determina a operacionalização do FSB é ainda mais recente. De modo complementar, 
alguns critérios descritivos são utilizados para expor as características do tema pesquisado, notadamente quando a operacionalização do FSB é investigada.

Gil (2008, p. 65) afirma que "a pesquisa bibliográfica é desenvolvida a partir de material já elaborado". De modo semelhante, a pesquisa documental recorre àquelas publicações que não receberam um tratamento analítico, mas que podem ser adequadamente formatadas para colaborar com os objetivos da pesquisa. Para a aproximação entre o FSB e os Fundos Soberanos, a pesquisa é realizada a partir de material publicado em livros, jornais, revistas e sites da internet. A pesquisa é igualmente documental, materializada através de documentos encontrados em órgãos públicos, notadamente STN e Banco Central do Brasil (BCB).

No entendimento de Vergara (2003), o pesquisador deve informar como os dados serão coletados para que o problema seja respondido. A pesquisa documental encontra apoio na utilização das plataformas online para encontrar artigos jornalísticos, entrevistas e outros documentos que de alguma maneira não foram produzidos com viés científico e acadêmico, mas em muito contribuem com o propósito do estudo.

As variáveis que expressam o valor econômico e financeiro são obtidas em publicações do SWF Institute (para os Fundos Soberanos), da STN (para o FSB) e do BCB (cenário macroeconômico). Os dados são tecnicamente formatados em tabelas e gráficos para atender os propósitos da pesquisa.

\section{Apresentação e Análise dos Dados}

A partir dos critérios internacionalmente consagrados para as boas práticas dos Fundos Soberanos, é traçado um paralelo com as práticas adotadas na concepção, gestão e operacionalização do FSB. A fim de identificar se o FSB é aderente aos conceitos dos Fundos Soberanos, os critérios são apresentados em forma de tabela e o comportamento dos Fundos Soberanos é confrontado com o comportamento do FSB. A análise dos dados conduz aos resultados apresentados na Tabela 1.

Tabela 1

Aderência do FSB aos critérios internacionais

\begin{tabular}{|c|c|c|c|}
\hline Critério & Fundos Soberanos & FSB & $\begin{array}{c}\text { FSB é } \\
\text { aderente? }\end{array}$ \\
\hline Fonte de Financiamento & $\begin{array}{c}\text { Superávit fiscal, saldo positivo no } \\
\text { Balanço de Pagamentos e/ou } \\
\text { exportação de commodities }\end{array}$ & $\begin{array}{c}\text { Financiado pela emissão de Títulos da } \\
\text { Dívida Pública }\end{array}$ & Não \\
\hline Resgates & $\begin{array}{c}\text { Mitigar efeitos negativos dos ciclos } \\
\text { econômicos }\end{array}$ & $\begin{array}{c}\text { Gerar superávit primário, contrariando } 0 \\
\text { Art. } 5^{\circ} \text { da Lei } 11.887 / 2008\end{array}$ & Não \\
\hline Disciplina Fiscal & Requisito para o sucesso do Fundo & $\begin{array}{l}\text { Concebido num cenário de indisciplina } \\
\text { fiscal }\end{array}$ & Não \\
\hline Reservas Internacionais & $\begin{array}{c}\text { Descolamento do Banco Central, } \\
\text { dívida externa líquida menor ou } \\
\text { igual a zero }\end{array}$ & $\begin{array}{c}\text { Recursos descolados das reservas } \\
\text { cambiais do BCB, mas relação entre } \\
\text { reservas externas e dívida líquida externa } \\
\text { não é elevada }\end{array}$ & Parcialmente \\
\hline $\begin{array}{l}\text { Elevado Retorno do } \\
\text { Capital Investido }\end{array}$ & $\begin{array}{c}\text { Menor aversão ao risco para } \\
\text { maximizar o retorno sobre o capital } \\
\text { investido }\end{array}$ & $\begin{array}{l}\text { Rentabilidade média de } 0,29 \% \text { a.m. desde } \\
\text { a sua criação e rentabilidade negativa } \\
\text { desde dezembro de } 2010 \text {, conforme o } \\
\text { Relatório de Desempenho do Fundo } \\
\text { Soberano do Brasil }\end{array}$ & Não \\
\hline Transparência & $\begin{array}{l}\text { Índice de Transparência Linaburg- } \\
\text { Maduell (escala de } 0 \text { a 10) }\end{array}$ & Nota 9 & Sim \\
\hline $\begin{array}{l}\text { Exploração de Recursos } \\
\text { Não Renováveis }\end{array}$ & $\begin{array}{l}\text { Aproximadamente } 60 \% \text { dos } \\
\text { recursos dos Fundos Soberanos } \\
\text { classificados pelo SWF Institute } \\
\text { têm origem na exploração do } \\
\text { petróleo }\end{array}$ & $\begin{array}{c}\text { Não commodity, capitalizado através da } \\
\text { emissão de títulos da dívida mobiliária } \\
\text { federal }\end{array}$ & Não \\
\hline
\end{tabular}


As diferenças e as semelhanças entre o Fundo Soberano do Brasil e os fundos soberanos internacionalmente consagrados

\begin{tabular}{|c|c|c|c|}
\hline Critério & Fundos Soberanos & FSB & $\begin{array}{c}\text { FSB é } \\
\text { aderente? }\end{array}$ \\
\hline Oportunidade Política & $\begin{array}{c}\text { Último critério a ser considerado } \\
\text { após o atendimento de todos os } \\
\text { critérios anteriores }\end{array}$ & $\begin{array}{c}\text { Oportunismo político que não atende aos } \\
\text { critérios técnicos, apesar da necessária } \\
\text { blindagem contra a corrupção e mau uso } \\
\text { dos recursos }\end{array}$ & Parcialmente \\
\hline
\end{tabular}

Fonte: Dos autores

É possível perceber que o FSB atende apenas a um dos critérios utilizados para testar a aderência às boas práticas internacionais, a transparência, tendo sido reprovado em todos os demais critérios.

A Figura 3 ilustra o momento histórico em que o FSB foi sacado para aportar recursos na CTU e, assim, colaborar com as metas legalmente estabelecidas para o superávit primário do ano de 2012.

Até novembro de 2012, os recursos do FSB eram essencialmente aplicados em ações da Petrobras (PETR4 e PETR3), no montante aproximado de R \$8,6 bilhões, e do Banco do Brasil (BBAS3), R $\$ 2,42$ bilhões. $O$ recurso residual de $\mathrm{R} \$ 3,50$ bilhões estava aplicado em títulos da dívida pública brasileira.

\section{Figura 3}

Composição do FSB no $4^{\circ}$ Trimestre de 2012

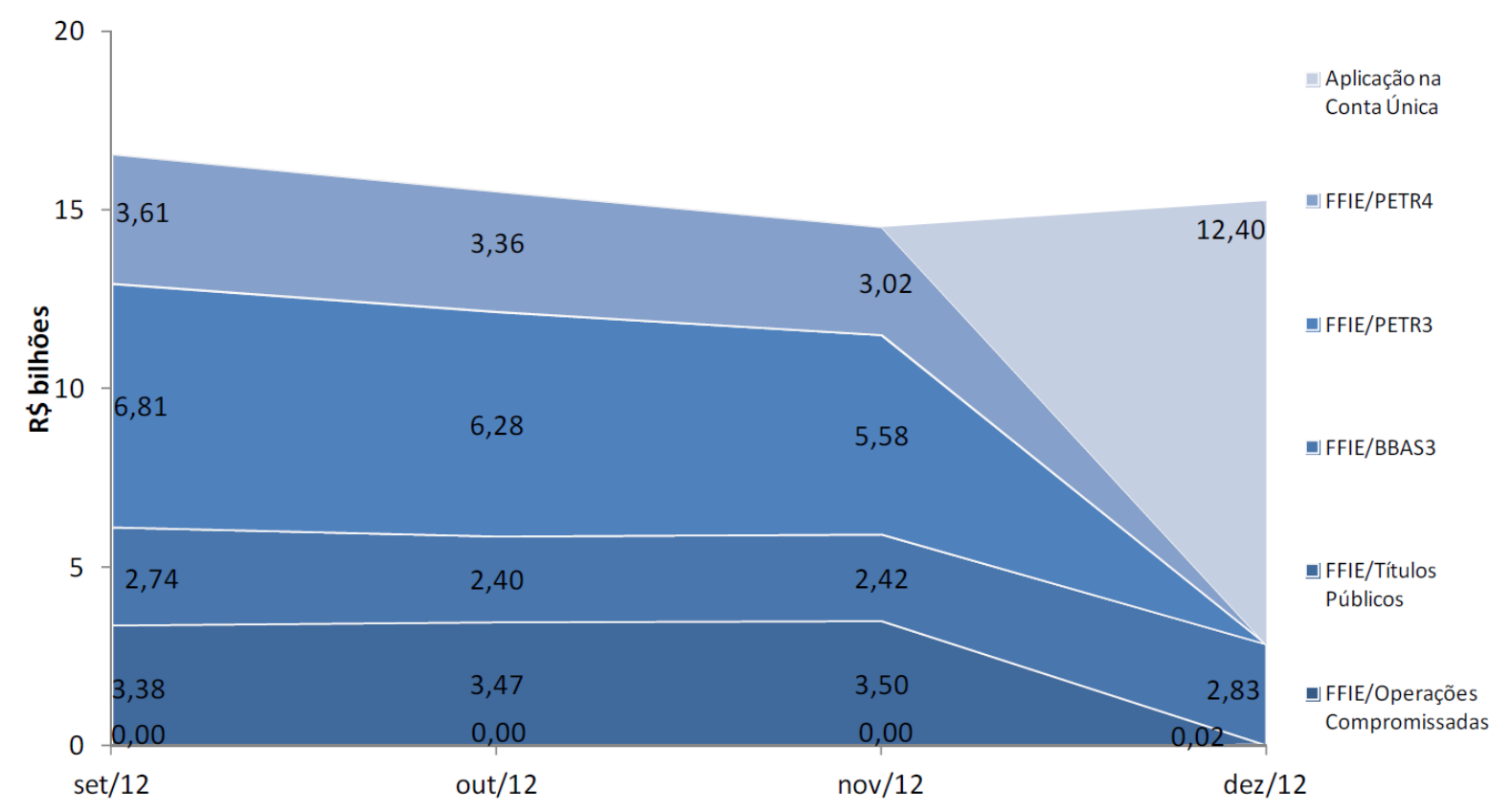

Fonte: Relatório de Desempenho do Fundo Soberano do Brasil - 4 Trimestre de 2012

Em novembro de 2012, as aplicações foram liquidadas, exceto as ações do Banco do Brasil (BBAS3), e os recursos foram depositados na CTU para que as metas fiscais estabelecidas na Lei de Diretrizes Orçamentárias (LDO) fossem cumpridas.

Percebe-se, pois, que a fonte de financiamento não é adequada, que ocorreu o resgate para cumprir meta legal de superávit, que o cenário é de indisciplina fiscal, que as reservas internacionais são reduzidas, que o retorno sobre o capital investido tem sido negativo nos últimos anos e que os recursos dos hidrocarbonetos fluídos da região do pré-sal não são utilizados. 


\section{Considerações Finais}

O texto apresenta o conceito de Fundos Soberanos e as características do FSB, para poder verificar a aderência deste último àqueles primeiros. O FSB foi concebido num cenário de indisciplina fiscal e reduzido saldo em Conta Corrente. A fantasiosa aplicação dos recursos na CTU sepultou definitivamente qualquer boa intenção que poderia haver na relação do FSB com a sociedade e com o mercado.

O Brasil é uma economia emergente potencialmente produtora de commodities, notadamente produtos agrícolas e petróleo, que começa a ser explorado na região do pré-sal. Apesar das mazelas sociais e da necessidade de investimento em educação e infraestrutura, a criação de um Fundo Soberano pode ser uma boa prática para o Brasil.

Todavia, os índices de desempenho da economia brasileira não justificam a criação de um Fundo Soberano com o perfil do FSB. É possível perceber que a criação do FSB não obedeceu aos critérios técnicos internacionalmente consagrados, condenando-o, assim, ao ostracismo.

$O$ estudo focou o lado da criação do FSB a partir dos conceitos internacionalmente consagrados. A limitação do estudo repousa no lado operacional dos Fundos Soberanos, qual seja a alocação de recursos ou Strategic Asset Alocation - SAA.

Entretanto, como sugestão para estudos futuros, é importante identificar o modelo adequado para que o Brasil possa estabelecer o seu Fundo Soberano com sucesso, fundamentado nas boas práticas internacionais de fonte de financiamento, aplicação dos recursos para estabilização e poupança para as gerações futuras, elevado retorno sobre o capital aplicado e blindagem contra a corrupção e contra o gasto público de baixa qualidade.

\section{Referências}

Al-Hassan, A., Papaioannou, M., Skancke, M., \& Sung, C. C. (2013). Sovereign Wealth Funds: Aspects of Governance Structures and Investment Management. IMF Working Paper.

Banco Central do Brasil. (2014). Economia e finanças. Disponível em: <http://www.bcb.gov.br/pt-br/Paginas/default.aspx>. Acesso em: 14 maio 2014.

Brasil. (2008). Lei 11.887/2008. Disponível em: <http://www.planalto.gov.br/ccivil_03/_ato2007-2010/2008/Lei/L11887.htm>. Acesso em: 14 maio 2014.

Brasil. (2012). Lei 12.465/2012. Disponível em: <http://www.planalto.gov.br/ccivil_03/_Ato2011-2014/2011/Lei/L12465.htm>. Acesso em: 14 maio 2014.

Brasil. (2000). Lei Complementar 101/200. Disponível em: <http://www.planalto.gov.br/ccivil_03/leis/lcp/lcp101.htm>. Acesso em: 14 maio 2014.

Caparica, R.F.C. (2010). O Papel dos Fundos Soberanos da Economia Mundial. 2010. 50 p. Dissertação (Mestrado em Finanças e Economia Empresarial) - Fundação Getúlio Vargas, Rio de Janeiro (RJ).

Chizzotti, A. (2000). Pesquisa em ciências humanas e sociais. 4 ed. São Paulo: Cortez.

Das, U. S., Mulder, C. B., Sy, A. N. R., \& Lu, Y. (2009). Setting up a Sovereign Wealth Fund: Some Policy and Operational Considerations. IMF Working Paper.

Freitas, P. S. (2009). Rendas do petróleo, questão federativa e instituição de fundo soberano. Consultoria do Senado Federal.

Gil, A. C. (2008). Métodos e técnicas de pesquisa social. São Paulo: Atlas.

Lopes, C. F. B. G. (2009). Sobre o Fundo Soberano do Brasil. 2009. 34 f. Dissertação (Mestrado em Economia). Faculdade de Economia, Administração, Contabilidade e Ciência da Informação e Documentação, Universidade de Brasília, Brasília.

Magalhães, A. S. (2010). Determinantes dos Fundos Soberanos de Investimentos e o Caso Brasileiro. 2010. 84 p. Dissertação (Mestrado em Comunicação) - Universidade de Brasília, Brasília (DF). 


\title{
As diferenças e as semelhanças entre o Fundo Soberano do Brasil e os fundos soberanos internacionalmente consagrados
}

Ministério da Fazenda. (2014). Fundo Soberano do Brasil. Disponível em: <http://www.tesouro.fazenda.gov.br/fundo_soberano/ index.asp>. Acesso em: 14 maio 2014.

Ministério da Fazenda. (2013). Relatório de Desempenho do Fundo Soberano do Brasil $3^{\circ}$ Trimestre de 2013. Secretaria do Tesouro Nacional, 2013.

Ministério das Relações Exteriores. (2014). Agrupamento BRICS. Mecanismos Inter-regionias.

Ministério do Planejamento, Orçamento e Gestão. (2014). Glossário. Secretaria de Orçamento Federal.

Morgan, G. (2005). Paradigmas, metáforas e quebra-cabeças na teoria das organizações. (1980) São Paulo: Revista de Administração de Empresa, v. 45, n. 1, Jan/Mar.

Murphy, S. A. (2012). Leviathan's double bottom line: Sovereign Wealth Funds as tools of strategic statecraft. Dissertação (Mestrado em Administração) - MIT Sloan School of Management, Massachusetts Institute of Technology, Massachusetts, 52 p.

PricewaterhouseCoopers. (2014). PwC: Global assets under management (AuM) to exceed $\$ 100$ trillion by 2020 with nearly 50 percent residing in North America. Press releases.

Sovereign Wealth Fund Institute. (2014). Fund rankings. Disponível em: <http://www.swfinstitute.org/fund-rankings/>. Acesso em: 14 maio 2014.

Sovereign Wealth Fund Institute. (2014). What is a SWF? Disponível em: <http://www.swfinstitute.org/sovereign-wealth-fund/>. Acesso em: 14 maio 2014.

Vergara, S. C. (2003). Projetos e relatórios de pesquisa em administração. 4 ed. São Paulo: Atlas.

Vergara, S. C. (2005). Métodos de pesquisa em administração. São Paulo: Atlas.

Vieira, J. (2008). Ranking mundial de juros reais. UPTREND Consultoria Econômica.

\section{DADOS DOS AUTORES}

\section{Jayme Luiz Gomes Fialho}

Mestre em Administração pela Faculdade Novos Horizontes

Analista Administrativo da Agência Nacional do Petróleo, Gãs Natural e Biocombustíveis

Endereço: Av. Afonso Pena, 867 - $9^{\circ}$ andar - Centro

CEP: 30130-002 - Belo Horizonte - MG

E-mail: jfialho@anp.gov.br

Telefone: (31) 3878-1350

\author{
Alfredo Alves de Oliveira Melo \\ Doutor em Ciências das Organizações pela Universite de Paris IX \\ Professor do Mestrado em Administração da Faculdade Novos Horizontes \\ Endereço: Rua Alvarenga Peixoto, 1270 - Santo Agostinho \\ CEP: 30180-121 - Belo Horizonte - MG \\ E-mail: diretoria@unihorizontes.br \\ Telefone: (31) 3349-2900
}




\section{Contribuição dos Autores:}

\begin{tabular}{lcc}
\hline Contribuição & Jayme Fialho & Alfredo Melo \\
\hline 1. Concepção do assunto e tema da pesquisa & $\sqrt{ }$ & $\sqrt{ }$ \\
2. Definição do problema de pesquisa & $\sqrt{ }$ & \\
$\begin{array}{l}\text { 3. Desenvolvimento das hipóteses e constructos da } \\
\text { pesquisa (trabalhos teórico-empíricos) }\end{array}$ & $\sqrt{ }$ & \\
$\begin{array}{l}\text { 4. Desenvolvimento das proposições } \\
\text { (trabalhos teóricos os ensaios teóricos) }\end{array}$ & & \\
$\begin{array}{l}\text { 5. Desenvolvimento da plataforma teórica } \\
\text { 6. Delineamento dos procedimentos metodológicos }\end{array}$ & $\sqrt{ }$ \\
$\begin{array}{l}\text { 7. Processo de coleta de dados } \\
\text { 8. Análises estatísticas }\end{array}$ & $\sqrt{ }$ \\
$\begin{array}{l}\text { 9. Análises e interpretações dos dados coletados } \\
\text { 10. Considerações finais ou conclusões da pesquisa }\end{array}$ & $\sqrt{ }$ & \\
11. Revisão crítica do manuscrito & $\sqrt{ }$ \\
12. Redação do manuscrito & & \\
\end{tabular}

